\title{
Article \\ Physical Activity, Stress, Depression, Emotional Intelligence, Logical Thinking, and Overall Health in a Large Lithuanian from October 2019 to June 2020: Age and Gender Differences Adult Sample
}

\author{
Albertas Skurvydas ${ }^{1,2}$, Ausra Lisinskiene ${ }^{1,3, * \mathbb{D}}$, Marc Lochbaum ${ }^{1,3,4} \mathbb{D}$, Daiva Majauskiene ${ }^{1,5}$, Dovile Valanciene ${ }^{1,6} \mathbb{( D}^{\mathbb{D}}$, \\ Ruta Dadeliene ${ }^{2}$, Natalja Fatkulina ${ }^{7}$ (D) and Asta Sarkauskiene ${ }^{8}$ (D)
}

check for

updates

Citation: Skurvydas, A.; Lisinskiene,

A.; Lochbaum, M.; Majauskiene, D.;

Valanciene, D.; Dadeliene, R.;

Fatkulina, N.; Sarkauskiene, A.

Physical Activity, Stress, Depression,

Emotional Intelligence, Logical

Thinking, and Overall Health in a

Large Lithuanian from October 2019

to June 2020: Age and Gender

Differences Adult Sample. Int. J.

Environ. Res. Public Health 2021, 18,

12809. https://doi.org/10.3390/

ijerph182312809

Academic Editor: Shaher A.

I. Shalfawi

Received: 5 November 2021

Accepted: 24 November 2021

Published: 4 December 2021

Publisher's Note: MDPI stays neutral with regard to jurisdictional claims in published maps and institutional affiliations.

Copyright: (c) 2021 by the authors. Licensee MDPI, Basel, Switzerland. This article is an open access article distributed under the terms and conditions of the Creative Commons Attribution (CC BY) license (https:/ / creativecommons.org/licenses/by/ $4.0 /)$.
1 Education Academy, Vytautas Magnus University, K. Donelaičio Street 58, 44248 Kaunas, Lithuania; albertas.skurvydas@vdu.lt (A.S.); marc.lochbaum@ttu.edu (M.L.); daiva.majauskiene@vdu.lt (D.M.); dovile.valanciene@gmail.com (D.V.)

2 Department of Rehabilitation, Physical and Sports Medicine, Faculty of Medicine, Institute of Health Sciences, Vilnius University, 21/27 M.K. Čiurlionio St., 03101 Vilnius, Lithuania; ruta.dadeliene@mf.vu.lt

3 Institute of Educational Research, Education Academy, Vytautas Magnus University, K. Donelaičio Street 58, 44248 Kaunas, Lithuania

4 Department of Kinesiology and Sport Management, Texas Tech University, Lubbock, TX 79409-3011, USA

5 Department of Physical and Social Education, Lithuanian Sports University, Sporto Street 6, 44221 Kaunas, Lithuania

6 Institute of Sport Science and Innovations, Lithuanian Sports University, Sporto Street 6, 44221 Kaunas, Lithuania

7 Institute of Health Sciences, Faculty of Medicine, Vilnius University, 21/27 M.K. Čiurlionio Street, 03101 Vilnius, Lithuania; natalja.fatkulina@mf.vu.lt

8 Department of Sports, Recreation and Tourism, Klaipejda University, Herkaus Manto Street 84, 92294 Klaipėda, Lithuania; asta.sarkauskiene@ku.lt

* Correspondence: ausra.lisinskiene@vdu.lt; Tel.: +370-650-21236

Abstract: This study aimed to examine relationships and group differences among adult people's (aged 18-74) physical activity (PA), expression of stress, depression, emotional intelligence (EI), logical thinking (LT), and overall health assessment. Two hypotheses were formulated before the study. The first hypothesis is that overweight and obesity in young adults (18 to 34 years) females and males, in particular, should increase sharply and this should be associated with decreased PA, abruptly deteriorating subject health, increased stress, depression, and poorer emotion management and EI. Second hypothesis: We further thought that the better people's reflective thinking, the more they should live a healthier life (e.g., exercise more and eat healthier), their overweight and obesity should be small or none. We aimed to confirm or reject these two hypotheses. We applied a quantitative cross-sectional study design. The study results revealed that during the lifespan of 18-24 and 25-34 years (young adults) there was a sharp increase in overweight and obesity, a decrease in PA (and especially vigorous physical activity (VPA)) (and this was particularly evident in the male), while research participants felt less stress and depression, subjective assessment of health did not change, and EI increased steadily with age (18-24 to 65-74 years). The higher the EI of the research participants from 18-24 to 65-74 years of age the higher their moderate-to-vigorous physical activity (MVPA), the less stress and depression they felt. Based on the results, it can be said that both females and males prefer PA "with a hot heart rather than a cold mind." We base this conclusion on the fact that females and males who have the highest EI also have the highest MVPA while LT is not associated with MVPA.

Keywords: moderate-to-vigorous physical activity; physical health perceptions; mental health; cognitive functioning; personality 


\section{Introduction}

There is growing evidence-based research that various forms and doses of PA are effective in combating many chronic diseases [1-3], improving well-being and mental health [4-6], improving emotional well-being [7], and reducing all-cause mortality [8,9]. It was found that the effect of PA on various body functions is quite specific (i.e., depends in a non-linear manner on muscle work intensity, duration, and load "doses") [1,3,10]. In addition, the health benefits of PA also depend on people's age, gender, health, and body mass index (BMI) $[3,4,8,11,12]$. However, the lack of PA can negatively affect people's wellbeing and their overall health. The Word Health Organization (WHO) recommendations highlight that adult people must be physically active at least 150 min per week [3]. However recent studies have shown [3] that worldwide adult people do not meet WHO recommendations.

One recent meta-analysis showed a rising trend in the overall prevalence of obesity since the 1990s and this trend was more drastic in young adult female and male individuals [13]. It has been clearly shown that lack of PA increases the incidence and subsequently causes systemic inflammation of the body, which causes many chronic diseases $[1,14,15]$. Moreover, depressive symptoms are often associated with obesity, and emotional eating may play a considerable role in weight gain [16]. In addition, [17] have found that emotional eating (i.e., eating in response to negative emotions) is one mechanism linking depression and subsequent development of obesity. However, studies have rarely examined this mediation effect in a prospective setting and its dependence on other factors linked to stress and its management. The researchers [17] concluded that emotional eating is one behavioral mechanism between depression and development of obesity and abdominal obesity. Moreover, adults with a combination of shorter night sleep duration and higher emotional eating may be particularly vulnerable to weight gain. In relation to this, researchers [18] found that stress awareness was significantly associated with weight gain among women, while other psychological factors were not significantly associated with weight gain. Among women with overweight and obesity, stress is the main variable associated with excessive gestational weight gain [19].

Based on the [20] results, there is an urgent need for local and culturally contextualized interventions to address the complex risk factors that impact being overweight and obese, including the nutrition of at-home cooking, specific physical activity barriers, such as finding time, and perceptions of healthy weight for reducing the risk of long term cardiovascular disease. The researchers [21] summarized the dynamics of the 1.9 million human physical inactivities from 2001 to 2016: In developed European countries, it increased significantly for both males and females. Obesity and low PA can be intertwined (i.e., low PA stimulates obesity, while obesity has reduced people's motivation to be PA [22], and stimulates more frequent overeating due to the inability to suppress eating cravings [23]). Evidence from epidemiological studies indicates that depression and obesity have a strong bidirectional relationship (i.e., BMI increases the risk for developing depression, and vice versa, individuals with depression have an increased risk of high BMI) [24]. Stress and negative emotions during childhood pose a major threat to public health since they have been related not only to psychological disease but also to physiological disturbances such as obesity [25].

Based on the findings of the studies cited above, two hypotheses have been highlighted forward. The first hypothesis: Overweight and obesity in young adults-from 18 to 34 years-females and males, in particular, should increase sharply and this should be associated with decreased PA, abruptly deteriorating subject health, increased stress, depression, and poorer emotion management/EI. Second hypothesis: Since human choices are not necessarily influenced by a rational/reflective mind (explicit knowledge), but it often depends on implicit knowledge (i.e., from EI, impulsivity $[26,27]$ ), we further thought that the better people's reflective thinking, the more they should live a healthier life (e.g., exercise more and eat healthier) (i.e., their overweight and obesity should be small or none). The study aims to confirm or reject these two hypotheses. 
This research to our knowledge is the only one which presents the Lithuanian adult people sample in relation to PA, weight and obesity, expression of stress and depression as well as the health assessment. It presents the overall picture of Lithuanian situation regarding PA in adult people context.

\section{Materials and Methods}

\subsection{Participants}

The participants were 6369 research participants $($ females $=4545$ and males $=1824)$ between the ages of 18- and 74-year-old (Figure 1) completed correctly. The investigations were conducted from October 2019 to June 2020. The participants were included from Lithuania country to represent the Lithuanian sample. Participation was anonymous. Thus, data collection and handling were confidential. We used an online survey to collect information through https:/ / docs.google.com/forms / (accessed on 1 March 2020). All participants completed the online questionnaires. An online survey using the Google Forms platform.

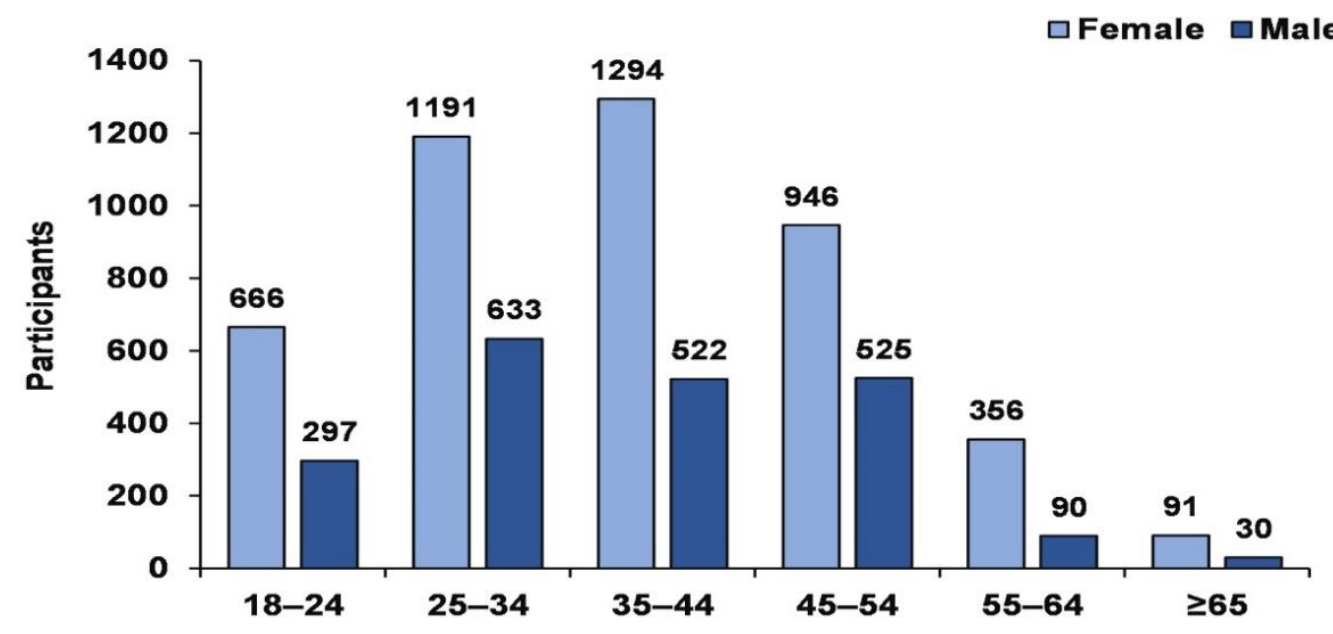

Figure 1. Research participant sample sizes by age groups by gender.

\subsection{Procedure}

Ethic committee approval to conduct this research was provided by the Klaipeda University (protocol No. STIMC-BTMEK-08). Besides, we ensured that the study was performed according to the principles laid by declaration of Helsinki [28] and National guidelines for biomedical and health research involving human participants [29]. The purpose of the survey, introduction and about the length of the survey was added within the webbased open E-survey. A successful return of completed survey was considered as consent by the participant.

\subsection{Measures}

Danish Physical Activity Questionnaire (DPAQ). The DPAQ is adapted from the IPAQ instrument and differs from this by referring to PA of the last $24 \mathrm{~h}$ (for seven consecutive days) instead of the last 7 days [30] in metabolic equivalent (METs). One metabolic equivalent (MET) is defined as the amount of oxygen consumed while sitting at rest and is equal to $3.5 \mathrm{~mL} \mathrm{O} 2$ per $\mathrm{kg}$ body weight $\times$ in. The chosen activities were listed in the PA scale in nine levels of physical exertion, ranging from sleep or inactivity (0.9 MET) to strenuous activities ( $>6 \mathrm{METs})$. Each level $(\mathrm{A}=0.9 \mathrm{MET}, \mathrm{B}=1.0 \mathrm{MET}, \mathrm{C}=1.5 \mathrm{METs}$, $\mathrm{D}=2.0$ METs, $\mathrm{E}=3.0 \mathrm{METs}, \mathrm{F}=4.0 \mathrm{METs}, \mathrm{G}=5.0 \mathrm{METs}, \mathrm{H}=6.0 \mathrm{METs}$ and $\mathrm{I}>6 \mathrm{METs}$ ) was described by examples of specific activities of that particular MET level and by a small drawing.

The PA scale was constructed so that the number of minutes $(15,30$, or $45 \mathrm{~min})$ and hours (1-10 h) spent on each MET activity level on an average $24 \mathrm{~h}$ weekday could be filled 
out. This allowed for a calculation of the total MET-time, representing $24 \mathrm{~h}$ of sleep, work, and leisure time on an average weekday [31].

It has been calculated how much energy (METs) was consumed per day during sleeping, sedentary behavior (SB) (from 0.9 to 1.5 Mets), light-intensity physical activity (LPA) (from 1.5 to $5 \mathrm{METs}$ ), moderate-intensity physical activity (MPA) (from 3 to $6 \mathrm{METs}$ ), vigorous-intensity physical activity (VPA) (more than $6 \mathrm{METs}$ ). Besides, we have combined MPA and VPA (MVPA).

Subjective health assessment. A four-point scale was used for this: poor health (1 point); satisfactory ( 2 points), good (3 points); excellent (4 points).

Perceived stress and depression. The 10-item perceived stress scale (PSS-10) was used to measure participants' stress levels [32]. In the PSS-10, participants were asked to answer 10 questions about feelings and thoughts during the last month on Likert scale ranging from 0 (never) to 4 (very often), indicating how often they have felt or through a certain way within the past month. Scores range from 0 to 4 , higher scores indicate higher levels of perceived stress.

Assessment of emotional intelligence. EI was assessed using the Schutte self-report emotional intelligence test (SSREIT) [33]. The SSREIT is a 33-item questionnaire divided into four subscales: perception of emotion assessed by 10 items, managing own emotions assessed by 9 items, managing others' emotions assessed by 8 items, and utilization of emotions assessed by 5 items. The items are answered on a five-point scale ranging from 1 (strongly agree) to 5 (strongly agree). Total scores range from 33 to 165, with the higher scores indicating greater ability in EI.

Assessment of impulsivity. Impulsivity was assessed using the Barratt impulsiveness scale version 11 (BIS-11) [34]. The BIS-11 is a 30 -item questionnaire divided into three subscales: Attentional impulsiveness assessed by 8 items, motor impulsiveness assessed by 11 items, and non-planning impulsiveness assessed by 11 items. The items are answered on a four-point scale ranging from 1 (rarely/never) to 4 (almost always/always). Total scores range from 30 to 120, with higher scores representing higher impulsivity.

The Cognitive Reflection Test (CRT). The test tasks were developed according to the CRT test discussed in the article by [35]. The test consists of three tasks, which, after reading, automatically select the wrong answer. The author notes that it is possible to check what kind of thinking system a person uses. The first system reflects intuitive decisionmaking, which is usually fast, automatic, requires minimal effort, is implicit, and emotional. Meanwhile, the second system reflects reasoning that is slower, conscious, effort-intensive, goal-oriented, and logical. The test consists of three questions, for example: (1) A bat and a ball cost $\$ 1.10$ in total. The bat costs $\$ 1.00$ more than the ball. How much does the ball cost? ___ cents (2) If it takes 5 machines 5 min to make 5 widgets, how long would it take 100 machines to make 100 widgets? ___ minutes (3) In a lake, there is a patch of lily pads. Every day, the patch doubles in size. If it takes 48 days for the patch to cover the entire lake, how long would it take for the patch to cover half of the lake? ___ days. The measure is scored as the total number of correct answers. The cognitive reflection test (CRT) measures cognitive processing-specifically the tendency to suppress an incorrect, intuitive answer and come to a more deliberate, correct answer.

\subsection{Data Analysis}

Interval data are reported as the mean \pm standard error. All interval data were confirmed as being normally distributed using the Kolmogorov-Smirnov test. One-way and two-way ANOVA were performed to assess the effect of independent variables on the dependent variables of MVPA (METs). Calculations for observed power (OP) were performed; the partial eta squared $\left(\mathrm{y}_{P}^{2}\right)$ value was estimated as a measure of the effect size, and the B coefficient was estimated as a parameter of the regression. Chi-square $\left(\chi^{2}\right)$ tests were conducted to compare differences across sexes. The relationship between variables was also assessed with Pearson's correlation coefficient. For all tests, statistical significance 
was defined as $p<0.05$. Statistical analyses were performed using IBM SPSS Statistics software (version 22; IBM Corp., Armonk, NY, USA).

\section{Results}

\subsection{Health, Logic Task Solution, Impulsivity and EI: Differences between Gender}

Female and male values concerning health, logical task solution, impulsivity (BIS), and EI are described in Table 1. It has been found that men were statistically significantly better at assessing their health, solving logical problems better than women (Table 1). However, women had a statistically significantly higher EI. Interestingly, men and women did not differ in impulsivity.

Table 1. Descriptive average values in female and male: health, logical task solution, impulsivity (BIS), EI.

\begin{tabular}{|c|c|c|c|c|c|c|c|}
\hline & & \multicolumn{4}{|c|}{ Gender } & \multirow{3}{*}{ Chi-Square } & \multirow{3}{*}{$p$-Value } \\
\hline & & \multicolumn{2}{|c|}{ Female } & \multicolumn{2}{|c|}{ Male } & & \\
\hline & & $N$ & $\%$ & $N$ & $\%$ & & \\
\hline \multirow{4}{*}{$\begin{array}{c}\text { What is your health condition } \\
\text { for the last year? }\end{array}$} & Excellent & $760_{a}$ & $16.7 \%$ & $474_{\mathrm{b}}$ & $26.0 \%$ & \multirow{4}{*}{95.53} & \multirow{4}{*}{0.000} \\
\hline & Good & $2563 \mathrm{a}$ & $56.4 \%$ & $1010_{a}$ & $55.4 \%$ & & \\
\hline & Satisfactory & $1111_{\mathrm{a}}$ & $24.4 \%$ & $301_{b}$ & $16.5 \%$ & & \\
\hline & Poor & $112_{\mathrm{a}}$ & $2.5 \%$ & $39 \mathrm{a}$ & $2.1 \%$ & & \\
\hline \multirow{4}{*}{ Logic task solution } & None & 2000 & 44 & 683 & 37.4 & \multirow{4}{*}{30.90} & \multirow{4}{*}{0.000} \\
\hline & One & 1025 & 22.6 & 410 & 22.5 & & \\
\hline & Two & 715 & 15.7 & 327 & 17.9 & & \\
\hline & Three & 805 & 17.7 & 404 & 22.1 & & \\
\hline \multirow{4}{*}{ Impulsivity, BIS } & $<50$ & 908 & 20 & 212 & 14.1 & \multirow{4}{*}{2.10} & \multirow{4}{*}{0.54} \\
\hline & $50-59$ & 1875 & 41.3 & 906 & 52.2 & & \\
\hline & $60-69$ & 1336 & 29.4 & 552 & 32.8 & & \\
\hline & $>70$ & 426 & 9.4 & 154 & 10.9 & & \\
\hline \multirow{4}{*}{ Emotional intelligence } & $<100$ & 245 & 5.4 & 135 & 7.4 & \multirow{4}{*}{88.80} & \multirow{4}{*}{0.000} \\
\hline & $100-124$ & 1692 & 37.2 & 865 & 47.4 & & \\
\hline & $125-150$ & 2324 & 51.1 & 763 & 41.8 & & \\
\hline & $>150$ & 284 & 6.3 & 61 & 3.3 & & \\
\hline
\end{tabular}

Note: Values in the same row and sub-table not sharing the same subscript are significantly different at $p<0.05$ in the two-sided test of equality for column proportions. Cells with no subscript $(a, b)$ are not included in the test. Tests assume equal variances. Tests are adjusted for all pairwise comparisons within a row of each innermost sub-table using the Bonferroni correction.

\subsection{PA Determinants: Male vs. Female}

The results of the study showed that total METS per day was higher in male than in female, with age increasing (effect of Age: $p<0.0001 ; \mathrm{y}_{P}^{2}=0.026$; OP $=1$; effect of Gender: $p<0.0001 ; \mathrm{y}_{P}^{2}=0.007 ; \mathrm{OP}=1$; Age $\times$ Gender: $p=0.018 ; \mathrm{y}_{P}^{2}=0.002 ; \mathrm{OP}=0.82$ ) (Figures $2 \mathrm{~A}$ and 3 ).

It was found that younger adults (18-24 years of age) sleep more compared to adults $55-64$ years of age $(p<0.05)$ only for both female and male and there was no difference between males and females (effect of Age: $p<0.0001 ; \eta_{P}^{2}=0.011$; OP $=1$; effect of Gender: $p=0.134$; descriptive average values in female and 0.000; $\mathrm{OP}=0.31$; Age $\times$ Gender: $p=0.82$; $\left.\mathrm{y}_{P}^{2}=0.000 ; \mathrm{OP}=0.16\right)$ (Figures $2 \mathrm{~B}$ and 3$)$.

The results showed that METs of SB adults of 45-54 years of age SB is higher compared to adults of 65-74 years of age $(p<0.05)$ and there was no difference between male and female (effect of Age: $p<0.0001 ; \mathrm{y}_{P}^{2}=0.014 ; \mathrm{OP}=1$; effect of Gender: $p=0.11 ; \mathrm{y}_{P}^{2}=0.000$; $\mathrm{OP}=0.35$; Age $\times$ Gender: $p=0.25 ; \mathrm{y}_{p}^{2}=0.001 ; \mathrm{OP}=0.476$ (Figures $2 \mathrm{C}$ and 3 ). 


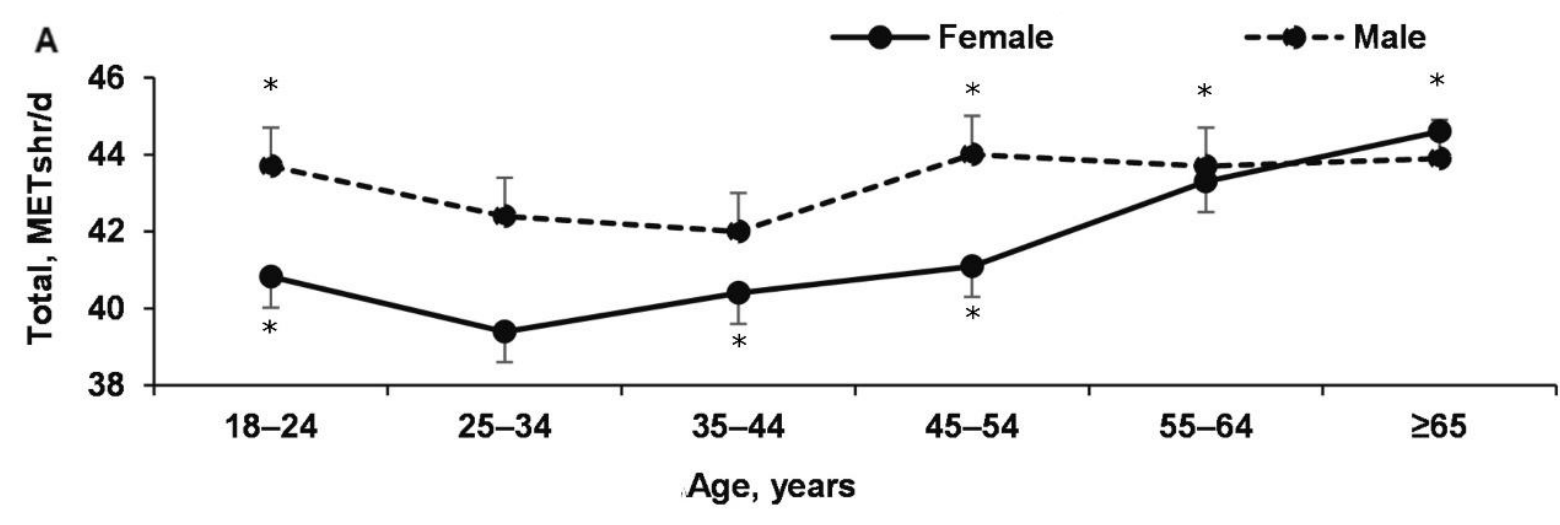

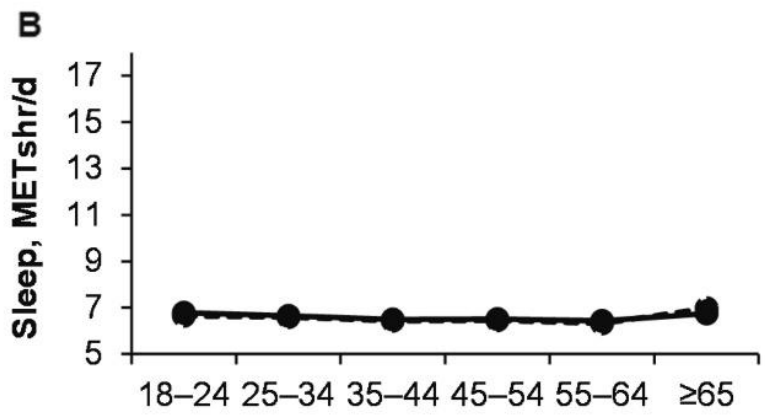

Age, years

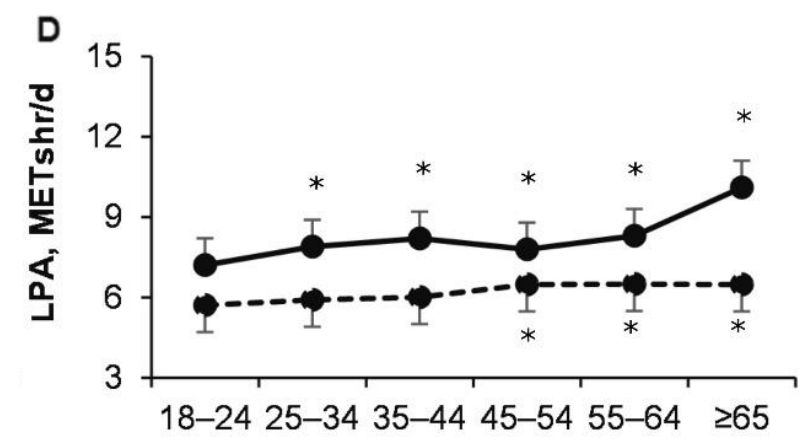

Age, years

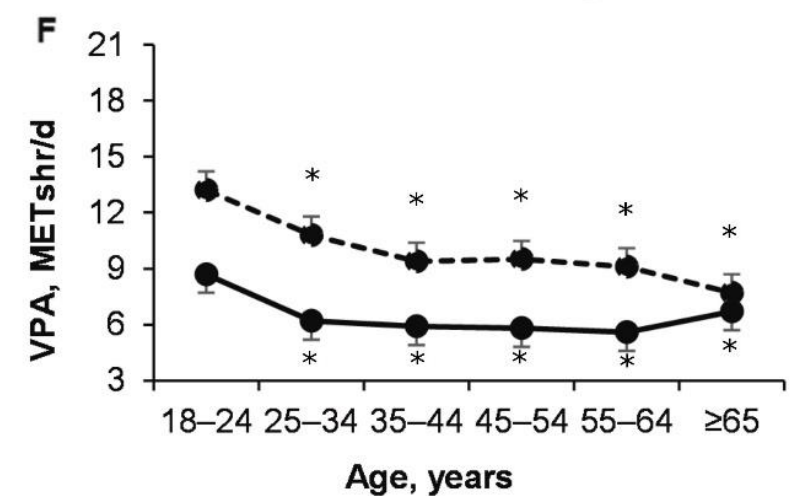

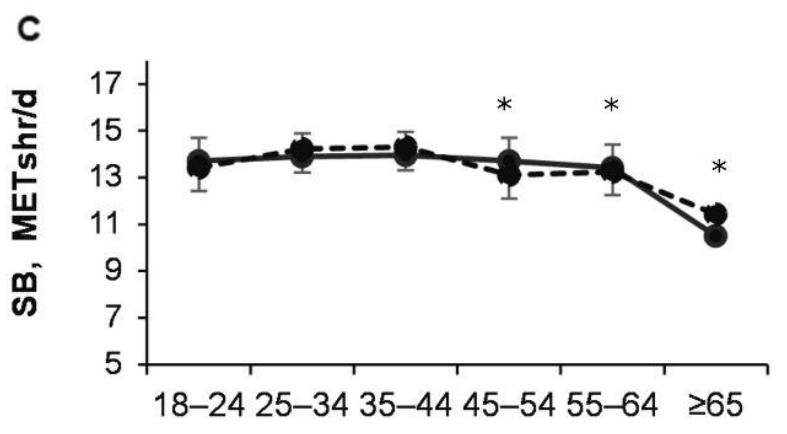

Age, years

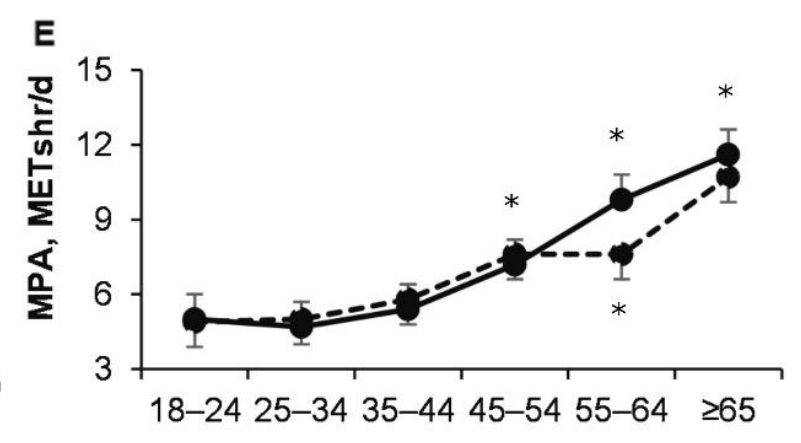

Age, years

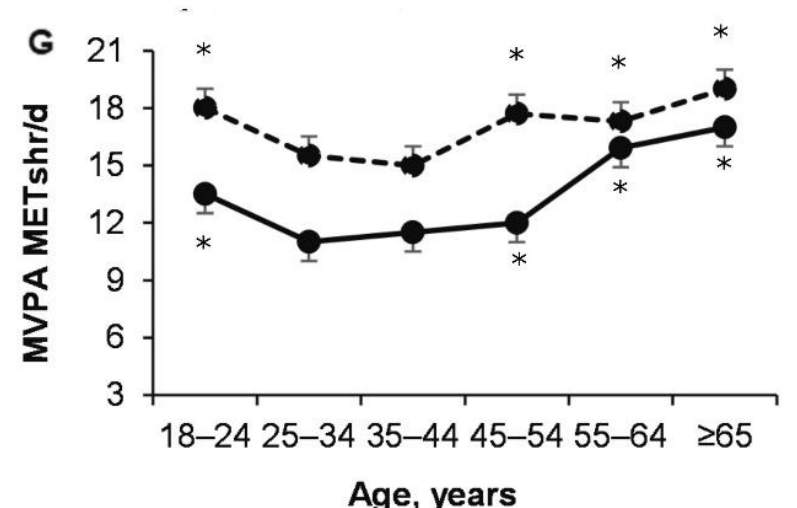

Figure 2. Changes during age total (A), sleep (B), SB (C), LPA (D), MPA (E), VPA (F), and MVPA (G) METs per day. (A). ${ }^{*}-p<0.05$ compared to male $25-44$ years and females compared to $25-34$ years; (C). ${ }^{*}-p<0.05$ compared to $18-44$ years; (D). ${ }^{*}-p<0.05$ compared to male 18-44 years and female with 18-24 years; (E). ${ }^{*}-p<0.05$ compared to 18-44 years; (F). ${ }^{*}-p<0.05$ compared to18-24 years; (G). ${ }^{*}-p<0.05$ compared to $25-44$ years. Note. Here in after: SB-sedentary behavior; LPA—light intensity physical activity; MPA—-moderate intensity physical activity; VPA—vigorous intensity physical activity; MVPA—moderate and vigorous intensity physical activity. 


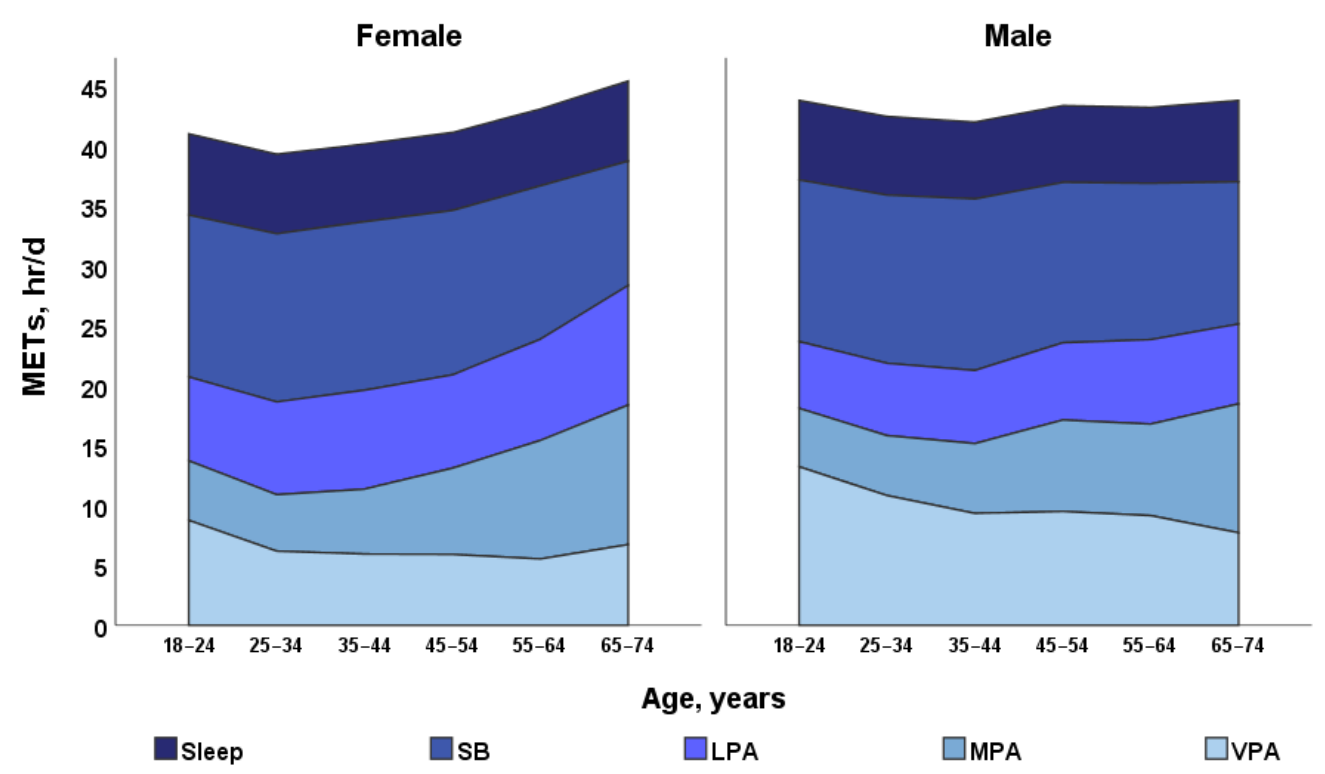

Figure 3. Sleep, SB, LPA, MPA, and MVPA changes in METs about gender and age differences.

LPA METs for female of all ages were higher than for male and increased with age for both male and female (effect of Age: $p<0.0001 ; \eta_{P}^{2}=0.007 ; \mathrm{OP}=1$; effect of Gender: $p<0.0001 ; \mathrm{\eta}_{P}^{2}=0.015 ; \mathrm{OP}=1 ;$ Age $\times$ Gender: $p=0.074 ; \mathrm{\eta}_{P}^{2}=0.002 ; \mathrm{OP}=0.68$ (Figures $2 \mathrm{D}$ and 3 ).

It is interesting to note that METs of MPA regarding age there was no difference between male and female (effect of Age: $p<0.0001 ; \mathrm{y}_{P}^{2}=0.016$; OP $=1$; effect of Gender: $p=0.13 ; \mathrm{y}_{P}^{2}=0.000 ; \mathrm{OP}=0.35 ;$ Age $\times$ Gender: $p=0.062 ; \mathrm{y}_{P}^{2}=0.002 ; \mathrm{OP}=0.71$ ) (Figures 2E and 3).

Research results showed that male (18-24 years of age) METs of VPA was higher than female from 18-24 years (effect of Age: $p<0.0001 ; \mathrm{y}_{P}^{2}=0.017$; OP $=1$; effect of Gender: $p<0.0001 ; \mathrm{y}_{P}^{2}=0.029 ; \mathrm{OP}=1 ;$ Age $\times$ Gender: $\left.p=0.287 ; \mathrm{\eta}_{P}^{2}=0.001 ; \mathrm{OP}=0.44\right)$ (Figures 2F and 3).

Research results showed that METs of MVPA were higher in male than in female and varied significantly with age (effect of Age: $p<0.0001 ; \eta_{P}^{2}=0.011 ; \mathrm{OP}=1$; effect Gender: $p<0.0001 ; \eta_{P}^{2}=0.061 ; \mathrm{OP}=1$; Age $\times$ Gender: $p=0.059 ; \mathrm{\eta}_{P}^{2}=0.002 ; \mathrm{OP}=0.708$ (Figures $2 \mathrm{G}$ and 3). Interestingly, for male and female aged 18-24 to 35-44 years, it decreased significantly and increased from $35-44$ to $65-74$ years $(p<0.05)$.

There are more non-athletic females than males $(p<0.05)$ (Table 2).

\subsection{Participation in Sports}

From 18-24 to 25-34 years, the number of non-athletes females was significantly low $(p<0.05)$ compared to independently exercising females $(p<0.05)$ (Table 2). Males prefer to do sports compared to females on their own (independently), but females prefer to play sports in sports clubs. The effect of age on participation in sports was significant in males and females (chi-square 101.6 and 169.9, respectively, $p<0.0001$ for both females and males).

\subsection{Changes in BMI during Age in Female and Male}

BMI significantly is higher of 55-64 years of adults compared to 18-24 years of age and continued to stabilize in both male and female (effect of Age: $p<0.0001 ; \mathrm{y}_{P}^{2}=0.066$; $\mathrm{OP}=1$ ) (Figure 4). BMI was higher in males (except 65-74 years) than in females of all ages (effect of Gender: $p=<0.0001 ; y_{P}^{2}=0.011 ; \mathrm{OP}=1$ ). With age, normal BMI and low BMI $\left(<20 \mathrm{~kg} / \mathrm{m}^{2}\right)$ decreased in males and females, overweight and obesity increased (chi-square female age effect 512.6, $p<0.0001$; male $-203.6, p<0.0001$ ) (Table 3). Besides, females with BMI were $<20 \mathrm{~kg} / \mathrm{m}^{2}$, there was more than males $(p<0.0001)$. Interestingly, for males with 
a BMI of $25-29.9 \mathrm{~kg} / \mathrm{m}^{2}$, it increased from 23.9 to $42.5 \%$, respectively, from 18-24 to $25-34$, compared with 11 to $16.3 \%$ among females (Table 3 ).

Table 2. Gender differences about participation in sports.

\begin{tabular}{|c|c|c|c|c|c|c|c|c|c|}
\hline \multirow{2}{*}{ Gender } & & & \multicolumn{4}{|r|}{ Age } & \multicolumn{3}{|l|}{ Years } \\
\hline & & & $18-24$ & $25-34$ & $35-44$ & $45-54$ & $55-64$ & $65-74$ & Total \\
\hline \multirow{8}{*}{ Female } & \multirow{2}{*}{ I do not exercise } & Count & $207 \mathrm{a}$ & $473_{\mathrm{b}}$ & $485_{a, b}$ & $377_{b}$ & $152_{\mathrm{b}}$ & $32 a, b$ & 1726 \\
\hline & & $\%$ & $31.1 \%$ & $39.7 \%$ & $37.5 \%$ & $39.9 \%$ & $42.7 \%$ & $35.2 \%$ & $38.0 \%$ \\
\hline & \multirow{2}{*}{ I am in a professional sport } & Count & $666_{a}$ & $46_{b}$ & $32_{b, c}$ & $8 \mathrm{c}$ & $1_{\mathrm{c}}$ & $1_{a, b, c}$ & 154 \\
\hline & & $\%$ & $9.9 \%$ & $3.9 \%$ & $2.5 \%$ & $0.8 \%$ & $0.3 \%$ & $1.1 \%$ & $3.4 \%$ \\
\hline & \multirow{2}{*}{ I exercise by myself } & Count & $239 \mathrm{a}$ & $337_{b}$ & $335_{b}$ & $272_{\mathrm{b}}$ & $116_{a, b}$ & $28_{\mathrm{a}, \mathrm{b}}$ & 1327 \\
\hline & & $\%$ & $35.9 \%$ & $28.3 \%$ & $25.9 \%$ & $28.8 \%$ & $32.6 \%$ & $30.8 \%$ & $29.2 \%$ \\
\hline & \multirow{2}{*}{ I exercise in a gym/health center } & Count & $154_{a}$ & $335_{a, b}$ & $443_{c}$ & $289_{b, c}$ & $87_{a, b}$ & $30_{a, b, c}$ & 1338 \\
\hline & & $\%$ & $23.1 \%$ & $28.1 \%$ & $34.2 \%$ & $30.5 \%$ & $24.4 \%$ & $33.0 \%$ & $29.4 \%$ \\
\hline \multirow{8}{*}{ Male } & \multirow{2}{*}{ I do not exercise } & Count & $46 \mathrm{a}$ & $128_{\mathrm{a}, \mathrm{b}}$ & $123_{\mathrm{a}, \mathrm{b}}$ & $60_{a, b}$ & $25_{a, b}$ & $12_{\mathrm{b}}$ & 394 \\
\hline & & $\%$ & $15.5 \%$ & $20.2 \%$ & $23.6 \%$ & $23.8 \%$ & $27.8 \%$ & $40.0 \%$ & $21.6 \%$ \\
\hline & \multirow{2}{*}{ I am in a professional sport } & Count & $56 a$ & $54_{\mathrm{b}}$ & $19 \mathrm{c}$ & $7_{\mathrm{c}}$ & $2 \mathrm{~b}, \mathrm{c}$ & $1_{a, b, c}$ & 139 \\
\hline & & $\%$ & $18.9 \%$ & $8.5 \%$ & $3.6 \%$ & $2.8 \%$ & $2.2 \%$ & $3.3 \%$ & $7.6 \%$ \\
\hline & \multirow{2}{*}{ I exercise by myself } & Count & $146 \mathrm{a}$ & $283 \mathrm{a}$ & $254_{a}$ & $134_{\mathrm{a}}$ & $44_{\mathrm{a}}$ & $14 \mathrm{a}$ & 875 \\
\hline & & $\%$ & $49.2 \%$ & $44.7 \%$ & $48.7 \%$ & $53.2 \%$ & $48.9 \%$ & $46.7 \%$ & $48.0 \%$ \\
\hline & \multirow{2}{*}{ I exercise in a gym/health center } & Count & $49 \mathrm{a}$ & $168_{\mathrm{b}}$ & $126_{a, b}$ & $51_{\mathrm{a}, \mathrm{b}}$ & $19 \mathrm{a}, \mathrm{b}$ & $3 a, b$ & 416 \\
\hline & & $\%$ & $16.5 \%$ & $26.5 \%$ & $24.1 \%$ & $20.2 \%$ & $21.1 \%$ & $10.0 \%$ & $22.8 \%$ \\
\hline
\end{tabular}

Each subscript letter $(a, b$, and $c)$ denotes a subset of one category whose column proportions do not differ significantly from each other at the 0.05 level.

3.5. Changes in Health, EI, Depression, Impulsivity, Perceived Stress and Reflexive Thinking (Logic Task Solution) with Age

Research results showed that male's health scores are better than female's (effect of Gender: $p=<0.0001 ; \eta_{P}^{2}=0.03$; OP $\left.=0.99\right)$, but for both male and female it decreased significantly since 55-64 years (effect of Age: $p<0.0001 ; \eta_{P}^{2}=0.011 ; \mathrm{OP}=1$; Age $\times$ Gender: $\left.p=0.42 ; y_{P}^{2}=0.001 ; \mathrm{OP}=0.36\right)($ Figure $5 \mathrm{~A})$.

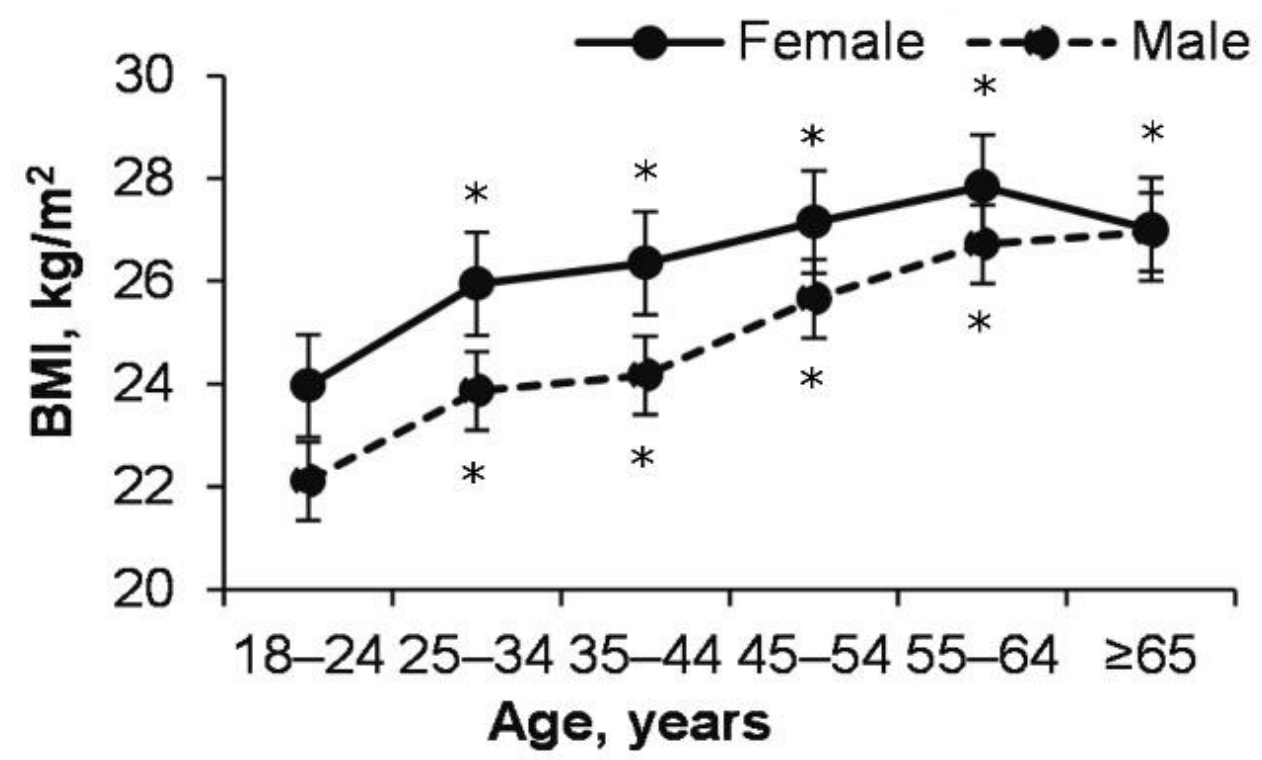

Figure 4. BMI changes during age. ${ }^{*} p<0.05$ compared to $18-24$ years. 
Table 3. BMI changes within an age.

\begin{tabular}{|c|c|c|c|c|c|c|c|c|}
\hline & \multirow{2}{*}{ BMI, $\mathrm{kg} / \mathrm{m}^{2}$} & & \multicolumn{4}{|r|}{ Age } & \multicolumn{2}{|l|}{ Years } \\
\hline & & & $18-24$ & $25-34$ & $35-44$ & $45-54$ & $55-64$ & $65-74$ \\
\hline \multirow{12}{*}{ Female } & \multirow{2}{*}{$<20$} & Count & $180_{a}$ & $250_{\mathrm{b}}$ & $185_{\mathrm{c}}$ & $61_{\mathrm{d}}$ & $11_{\mathrm{e}}$ & $1_{\mathrm{e}}$ \\
\hline & & $\%$ & $27.0 \%$ & $21.0 \%$ & $14.3 \%$ & $6.4 \%$ & $3.1 \%$ & $1.1 \%$ \\
\hline & \multirow{2}{*}{$20-24.9$} & Count & $389 a$ & $675_{a, b}$ & $685_{b}$ & $435_{c}$ & $131_{\mathrm{d}}$ & $36_{c, d}$ \\
\hline & & $\%$ & $58.4 \%$ & $56.7 \%$ & $52.9 \%$ & $46.0 \%$ & $36.8 \%$ & $39.6 \%$ \\
\hline & \multirow{2}{*}{$25-29.9$} & Count & $73 a$ & $194_{b}$ & $291_{\mathrm{c}}$ & $293_{\mathrm{d}}$ & $143_{\mathrm{e}}$ & $38_{\mathrm{e}}$ \\
\hline & & $\%$ & $11.0 \%$ & $16.3 \%$ & $22.5 \%$ & $31.0 \%$ & $40.2 \%$ & $41.8 \%$ \\
\hline & \multirow{2}{*}{$30-34.9$} & Count & $16 \mathrm{a}$ & $56_{\mathrm{b}}$ & $102_{c}$ & $113_{\mathrm{d}}$ & $53_{\mathrm{d}}$ & $7_{\mathrm{b}, \mathrm{c}, \mathrm{d}}$ \\
\hline & & $\%$ & $2.4 \%$ & $4.7 \%$ & $7.9 \%$ & $11.9 \%$ & $14.9 \%$ & $7.7 \%$ \\
\hline & \multirow{2}{*}{$35-39.9$} & Count & $6 a$ & $14_{\mathrm{a}}$ & $20_{a, b}$ & $26_{c}$ & $11_{b, c}$ & $7_{\mathrm{d}}$ \\
\hline & & $\%$ & $0.9 \%$ & $1.2 \%$ & $1.5 \%$ & $2.7 \%$ & $3.1 \%$ & $7.7 \%$ \\
\hline & \multirow{2}{*}{40 and more } & Count & $2 a, b$ & $2 \mathrm{~b}$ & $11_{\mathrm{a}, \mathrm{c}}$ & $18_{\mathrm{d}}$ & $7_{\mathrm{c}, \mathrm{d}}$ & $2_{c, d}$ \\
\hline & & $\%$ & $0.3 \%$ & $0.2 \%$ & $0.9 \%$ & $1.9 \%$ & $2.0 \%$ & $2.2 \%$ \\
\hline \multirow{12}{*}{ Male } & \multirow{2}{*}{$<20$} & Count & $26_{a}$ & $11_{\mathrm{b}}$ & $6_{b}$ & $1_{b}$ & $2 \mathrm{~b}$ & $0_{a, b}$ \\
\hline & & $\%$ & $8.8 \%$ & $1.7 \%$ & $1.1 \%$ & $0.4 \%$ & $2.2 \%$ & $0.0 \%$ \\
\hline & \multirow{2}{*}{$20-24.9$} & Count & $185 \mathrm{a}$ & $293_{b}$ & $194_{\mathrm{C}}$ & $72_{d}$ & $22_{d}$ & $10_{\mathrm{b}, \mathrm{c}, \mathrm{d}}$ \\
\hline & & $\%$ & $62.3 \%$ & $46.3 \%$ & $37.2 \%$ & $28.6 \%$ & $24.4 \%$ & $33.3 \%$ \\
\hline & \multirow{2}{*}{$25-29.9$} & Count & $71_{\mathrm{a}}$ & $269_{b}$ & $264_{\mathrm{c}}$ & $139_{c}$ & $43_{b, c}$ & $17_{b, c}$ \\
\hline & & $\%$ & $23.9 \%$ & $42.5 \%$ & $50.6 \%$ & $55.2 \%$ & $47.8 \%$ & $56.7 \%$ \\
\hline & \multirow{2}{*}{$30-34.9$} & Count & $12_{\mathrm{a}}$ & $52_{b}$ & $46_{b}$ & $31_{b, c}$ & $18_{\mathrm{c}}$ & $1_{a, b}$ \\
\hline & & $\%$ & $4.0 \%$ & $8.2 \%$ & $8.8 \%$ & $12.3 \%$ & $20.0 \%$ & $3.3 \%$ \\
\hline & \multirow{2}{*}{$35-39.9$} & Count & $3 a$ & $8 \mathrm{a}$ & $9 a$ & $7 \mathrm{a}$ & $2 a$ & $1_{a}$ \\
\hline & & $\%$ & $1.0 \%$ & $1.3 \%$ & $1.7 \%$ & $2.8 \%$ & $2.2 \%$ & $3.3 \%$ \\
\hline & \multirow{2}{*}{40 and more } & Count & $0_{a, b}$ & $\mathrm{O}_{\mathrm{b}}$ & $3_{a, b, c}$ & $2 \mathrm{a}, \mathrm{c}, \mathrm{d}$ & $3 \mathrm{~d}$ & $1_{\mathrm{c}, \mathrm{d}}$ \\
\hline & & $\%$ & $0.0 \%$ & $0.0 \%$ & $0.6 \%$ & $0.8 \%$ & $3.3 \%$ & $3.3 \%$ \\
\hline
\end{tabular}

Each subscript letter (a, b, c, d, and e) denotes a subset of one category whose column proportions do not differ significantly from each other at the 0.05 level.

Interestingly, EI was higher in female of all ages than in male $\left(p=<0.0001 ; \mathrm{y}_{P}^{2}=0.004 ;\right.$ $\mathrm{OP}=0.99$ ), however, for both female and male, it increased significantly from $18-24$ to 55-64 years (effect of Age: $p<0.0001 ; \eta_{P}^{2}=0.014 ; \mathrm{OP}=1$; Age $\times$ Gender: $p=0.96 ; \eta_{P}^{2}=0.000$; $\mathrm{OP}=0.096$ ) (Figure $5 \mathrm{~B}$ ).

Depression symptoms was lower in male than in female (effect of Age: $p<0.0001$; $\mathrm{\eta}_{P}^{2}=0.023 ; \mathrm{OP}=1$; effect of Gender: $p<0.0001 ; \mathrm{y}_{P}^{2}=0.03 ; \mathrm{OP}=0.99$; Age $\times$ Gender: $p=0.52$; $\mathrm{y}_{P}^{2}=0.001 ; \mathrm{OP}=0.31$ ) (Figure 5C).

Interesting to note that the impulsivity (BIS) did not depend on age or gender (effect of Age: $p=0.11 ; \mathrm{y}_{P}^{2}=0.011 ; \mathrm{OP}=1$; Gender: $p=0.741 ; \mathrm{\eta}_{P}^{2}=0.0000 ; \mathrm{OP}=0.063$. Age $\times$ Gender: $p=0.74 ; \eta_{P}^{2}=0.008 ; \mathrm{OP}=0.21$ ) (Figure 5D).

Research results showed that perceived stress was higher in adults of 18-24 years of age compared to $45-54$ years of age adults (effect of Age: $p<0.0001 ; \eta_{P}^{2}=0.02$; OP $=1$ ). Perceived stress in all female group were higher (effect of Gender: $p<0.0001 ; \mathrm{\eta}_{P}^{2}=0.003$; $\mathrm{OP}=0.98$; Age $\times$ Gender: $p=0.96 ; \mathrm{y}_{P}^{2}=0.000 ; \mathrm{OP}=0.09$ ) (Figure 5E)

Besides, it has been found that reflective thinking (logic task solution) has an impact regarding adult age: Younger adults' reflective thinking is higher than older adult people $\left(p=0.0041 ; \mathrm{y}_{P}^{2}=0.003 ; \mathrm{OP}=0.91\right)$, males scored higher (effect of Gender: $p=0.008$; $\mathrm{y}_{P}^{2}=0.000 ; \mathrm{OP}=0.75 ;$ Age $\times$ Gender: $\left.p=0.79 ; \mathrm{y}_{P}^{2}=0.000 ; \mathrm{OP}=0.18\right)($ Figure $5 \mathrm{~F})$. 

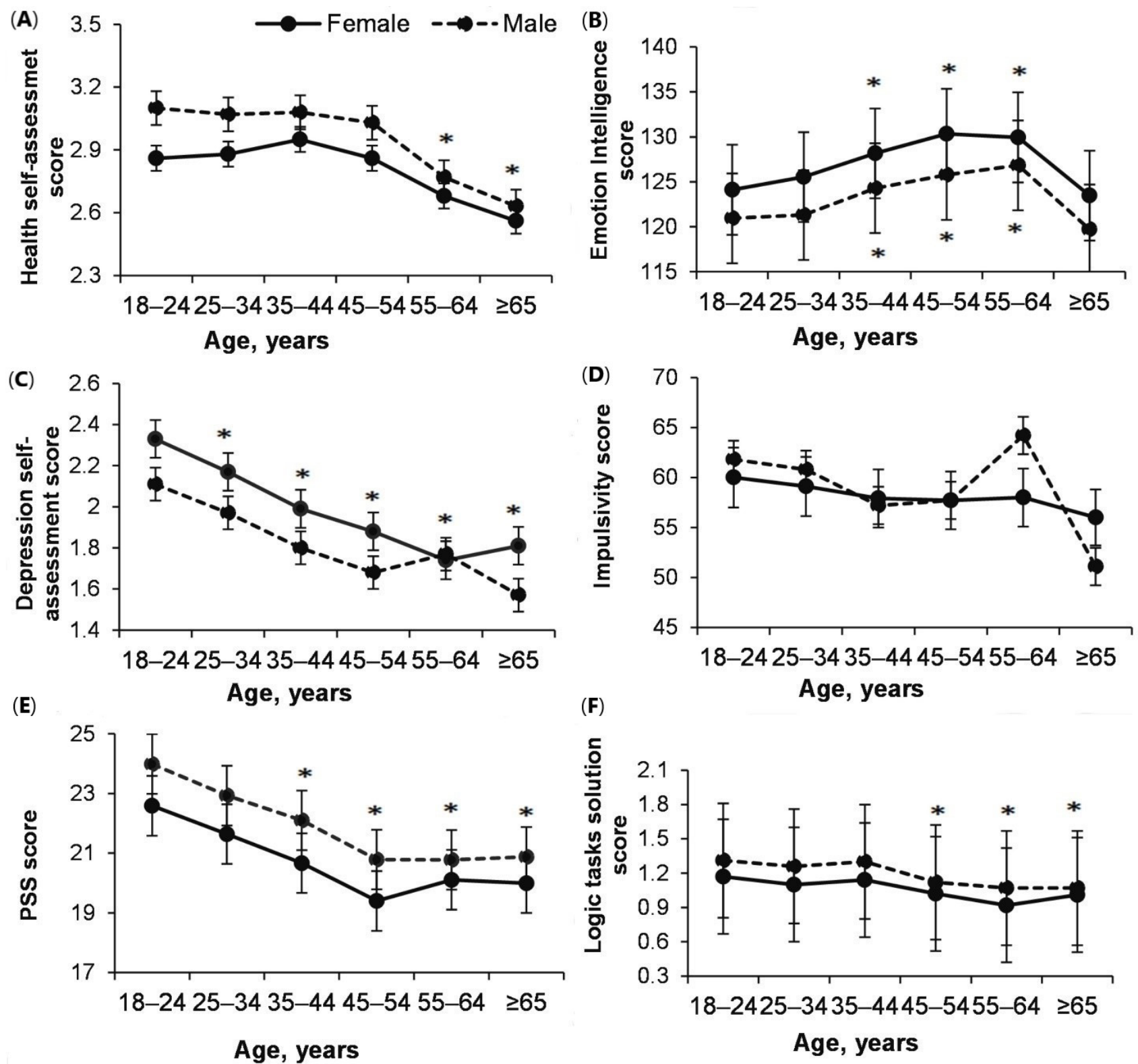

Age, years

Figure 5. Changes in health (A), emotional intelligence (EI) (B), depression (C), impulsivity (BIS) (D), perceived stress (E) and reflexive thinking (logic task solution) (F) within age. (A). ${ }^{*}-p<0.05$, compared to $18-24,25-34,35-44$; 45-54 years; (B). ${ }^{*}-p<0.05$, compared to $18-24,25-34$ and $65-74$ years; (C). ${ }^{*}-p<0.05$, compared to 18-24 years; (E). ${ }^{*}-p<0.05$, compared to 18-24, 25-34 years; (F). * $-p<0.05$, compared to 18-24, 25-34, 35-45 years.

\subsection{The Effect of BMI on Perceived Stress, Health and Depression}

Interestingly, perceived stress and depression in female was independent of BMI (Figure 6). Quite unexpected that even with a higher BMI in males, the lower the perceived stress and depression $(p<0.05)$ (Figure $6 \mathrm{~A}, \mathrm{C})$. In addition, a health assessment is, thus, independent of BMI (Figure 6B).

\subsection{The EI on Perceived Stress, MVPA, Depression and Health in Different Ages}

Research results showed that effect of EI on perceived stress is significant $(p<0.0001$; $\mathrm{y}_{P}^{2}=0.018 ; \mathrm{OP}=1 ;$ Age $\times$ EI: $\left.p=0.85 ; \eta_{P}^{2}=0.001 ; \mathrm{OP}=0.46\right)($ Figure $7 \mathrm{~A})$. 

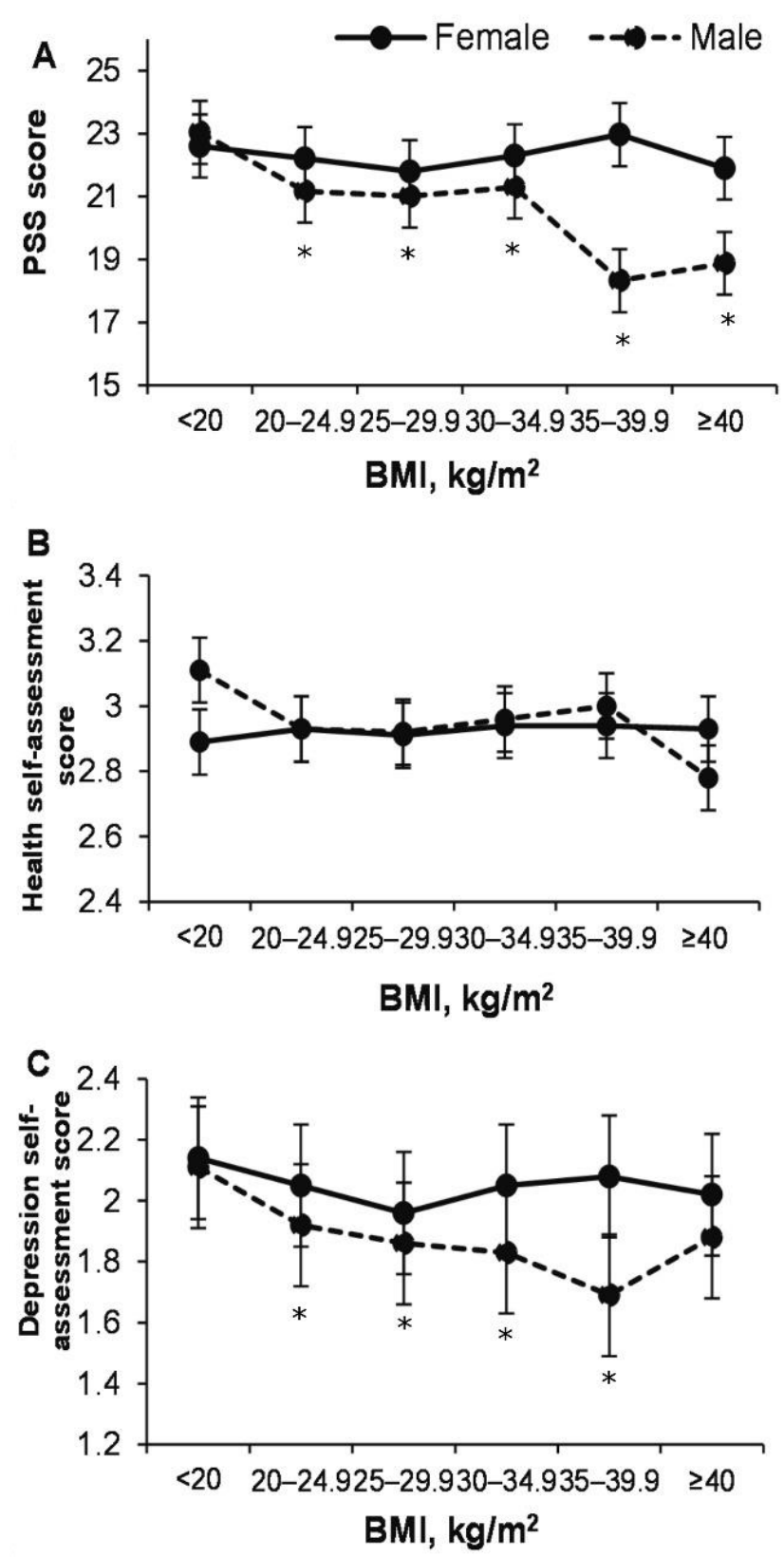

Figure 6. Relationship between BMI $\left(\mathrm{kg} / \mathrm{m}^{2}\right)$ and perceived stress (A), health (B), and depression (C). (A,C). ${ }^{*} p<0.05$, compared to $<20$ BMI.

Besides, the higher the EI, the higher the score of MVPA $\left(p<0.0001 ; \eta_{P}^{2}=0.006 ; \mathrm{OP}=1\right.$; Age $x$ EI: $p=0.91 ; y_{P}^{2}=0.001 ; \mathrm{OP}=0.37$ ) (Figure 7B).

Interestingly, the higher the EI, the lower all age groups' depression level $(p<0.0001$; $\mathrm{y}_{P}^{2}=0.014 ; \mathrm{OP}=1$; Age $\mathrm{xEI}: p=0.72 ; \mathrm{\eta}_{P}^{2}=0.002 ; \mathrm{OP}=0.53$ ) (Figure 7C).

We found that health condition did not depend on EI $\left(p=0.22 ; \eta_{P}^{2}=0.001 ; \mathrm{OP}=0.31\right)$; however, it was found that in relation to people 55-64 years of age, the higher the EI they reported, the higher and better health condition they stated $(p<0.05)$ (Figure 7D).

\subsection{The Effect of Reflective Thinking on MVPA and Depression during Different Ages}

The results of the study showed that MVPA of people of different ages does not depend on reflective thinking (logic solution task) (effect of reflective thinking: $p=0.74 ; \mathrm{\eta}_{P}^{2}=0.000$; $\mathrm{OP}=0.13$; Age $\times$ reflective thinking: $\left.p=0.81 ; \mathrm{y}_{P}^{2}=0.002 ; \mathrm{OP}=0.465\right)$ (Figure $8 \mathrm{~A}$ ). Besides, effect of reflective thinking on depression was also not significant $\left(p=0.56 ; \mathrm{y}_{P}^{2}=0.000\right.$; $\mathrm{OP}=0.21$; Age $\times$ reflective thinking: $p=0.59 ; \mathrm{y}_{P}^{2}=0.002 ; \mathrm{OP}=0.61$ ). (Figure $8 \mathrm{~B}$ ). 

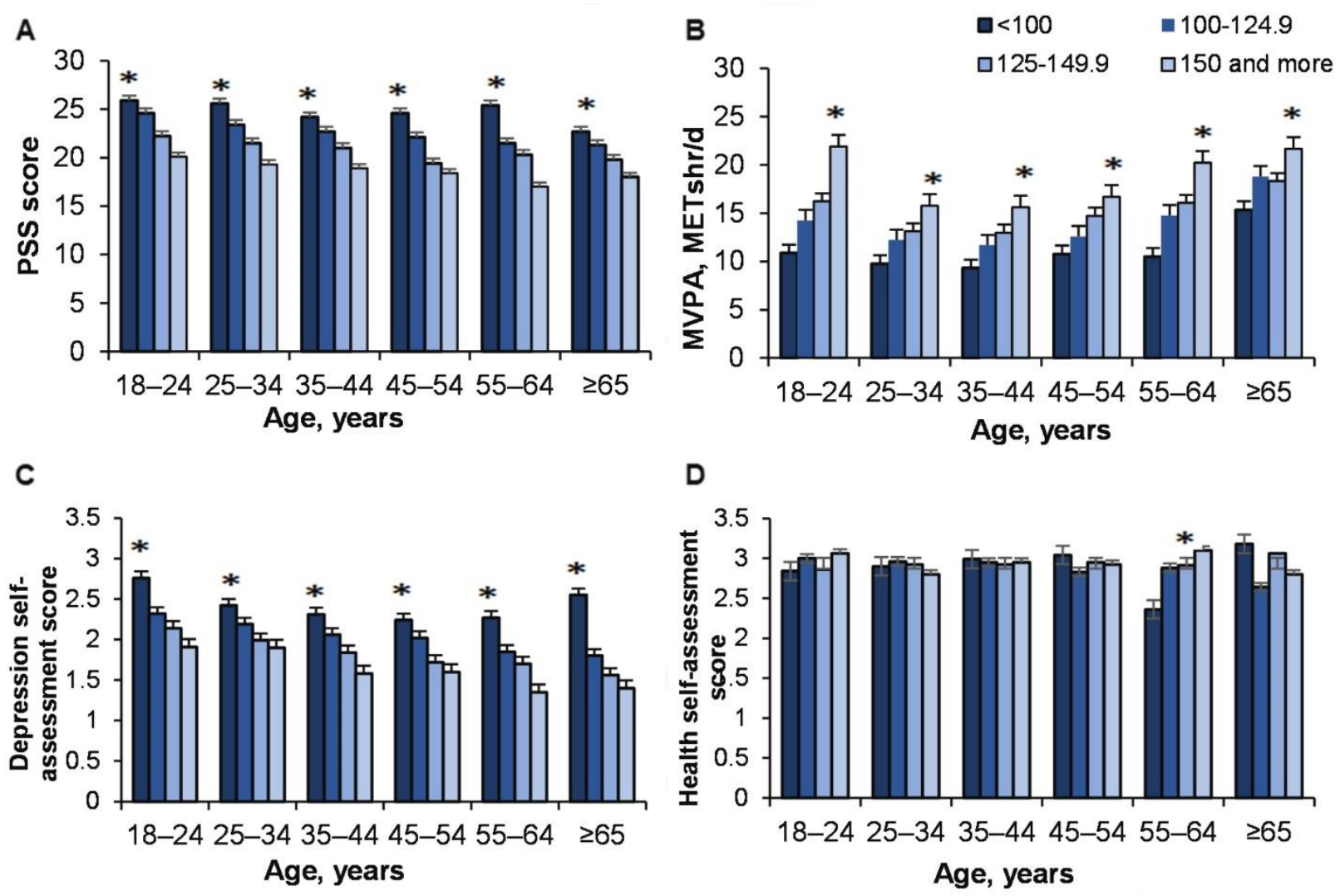

Figure 7. The effect of age and emotional intelligence (EI) on perceived stress (A), moderate and vigorous intensity PA (MVPA) (B), depression (C), and health (D). (A). ${ }^{*}-p<0.05$ compared to EI 100-150 and more; (B). ${ }^{*}-p<0.05$ compared to $\mathrm{EI}<150 ;(\mathrm{C}) .{ }^{*}-p<0.05$ compared to EI 100-150 and more; (D). ${ }^{*}-p<0.05$ compared to EI $<150$.
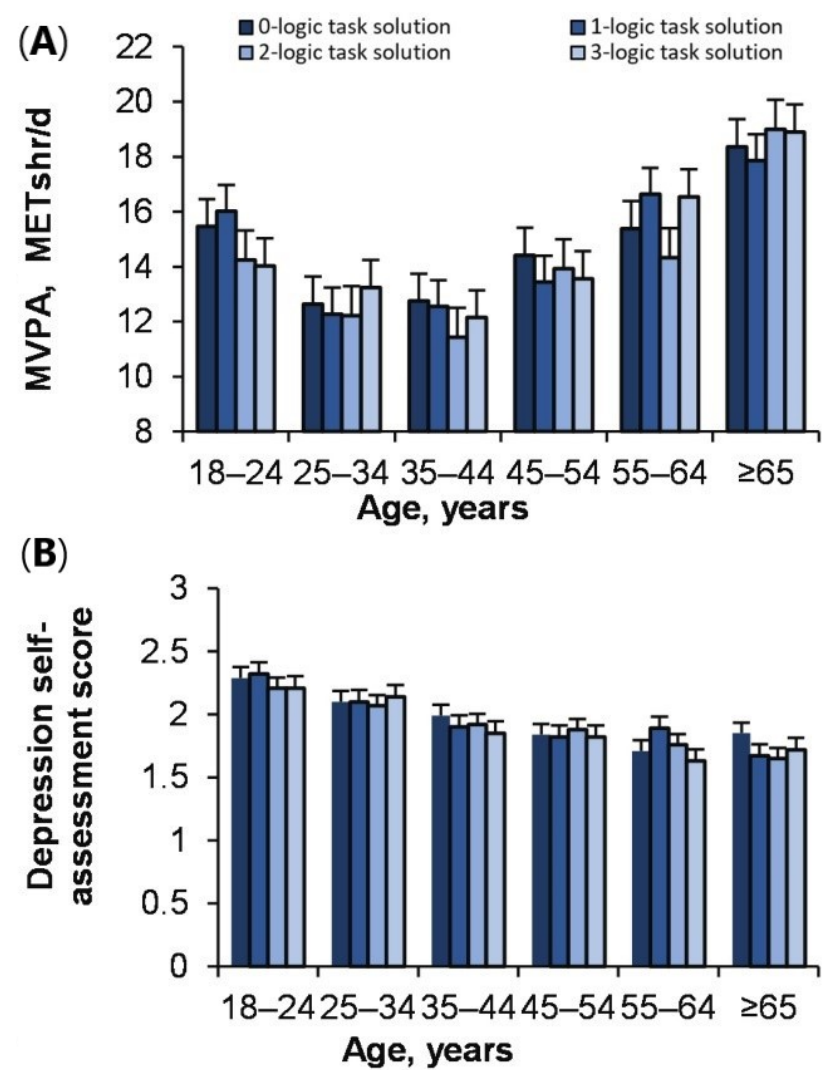

Figure 8. The age effect of logic task solution with MVPA (A) and depression (B). 


\section{Discussion}

This study aimed to examine Lithuanian adult people's (aged 18-74) PA, EI, expression of stress, depression, and their overall health status.

Study results showed that the structure of PA is different in males and females: Males have a higher VPA and females have a higher LPA (Figures 2 and 3). Males under 55 years old have a higher total daily energy expenditure and METs of MVPA than females. Higher PA in males is associated with more males exercising more independently.

Moreover, the BMI of a male of all ages (except 65-74 years) is higher than that of a female (Figure 4). From 18-24 to 55-64 years, BMI increased for both males and females. The number of males who are overweight increased sharply from 18-24 to 25-34 years (Table 3) and this is associated with a sharp decrease in daily energy expenditure in that age group (Figures 2 and 3 ).

In addition, health assessment (for both male and female) did not change from 18-24 to 45-54 (Figure 5A), while that between depression (Figure 5C) and perceived stress (Figure 5E) decreased steadily at that stage, with the decrease thought to be significantly influenced by the increase in EI with age (Figure 5B) (impulsivity did not change with reflective thinking decreased during life-span). Depression (Figure 7C) and perceived stress (Figure 7A) were the highest and MVPA (Figure 7B) the highest among people of all ages with the lowest EI. Interestingly, people of all ages with the highest EI had the same health outcomes and did not change during their lifespan (Figure 7D). Interestingly, health assessment did not depend on BMI (Figure 6B), and males with higher BMI even felt less stress (Figure 6A).

In general, our primary hypothesis was only partially confirmed then, as we expected, overweight and obesity in young adults-from 18 to 34 years-increased and especially in the male, and at the same time the lifespan interval decreased in MVPA (consistent with data from other researchers, [11]. Contrary to expectations, subjective health assessment did not change, and feelings of stress and depression decreased (for impulsiveness did not change with age). In addition, EI increased at that age and up to 74 years. We believe that the increase in EI with age has been gelled to "compensate" for the negative effects of an increase in BMI on subjective health assessment, less depression, and stress. People are experiencing a sudden increase in overweight and obesity, but EI (and of course other reasons) does not allow us to state it as "bad health". This is consistent with data from other researchers that various social and psychological factors have a positive effect on people's well-being over their lifespan [36]. In addition, during one's lifespan, different life goals and motives for achieving them appear. For example, between 18-24 and 25-34, both males and females face their first job, marriage, and the birth of a child [37], which may contribute to a decrease in MVPA. Besides, the PA of humans is influenced by several interrelated determinants such as demographic, health and health behavior, psychological, social, environmental, and determinants related to the intervention [12,38,39]. In addition, studies by Stone et al., 2017 show that Americans sense of stress increased from 20 to 50 years of age and began to decrease from 50 years of age. However, in our case, the stress started to decrease steadily from the age of 18-24 to 65-74.

Research results completely reject the second hypothesis, where increasing BMI with age, reflective thinking even decreased. Interestingly, the higher the BMI in males, the lower the stress and depression (Figure 6A,B). In our case, with a sharp increase in BMI from 18-24 to 25-44 years and a decrease in PA, it would appear that people are about to make an explicit decision to combat the severity of a very important chronic disease (obesity) [40]. Therefore, we can only speculate that people decided to do PA or not based more on implicit knowledge rather than explicit (reflective thinking), because implicit thinking requires less effort, it is more psychologically attractive [26,27]. Research by [41] has shown that people who cope well with stress and have an increased BMI have better cardiovascular health than those who do not manage stress and have a healthy BMI. The fact that our research findings show that females felt less depressed than males coincides with the work of other researchers [42]. Therefore, it can be said that both females and 
males prefer PA "with a hot heart rather than a cold mind." We base this conclusion on the fact that females and males who have the highest EI also have the highest MVPA, although LT is not associated with MVPA. This conclusion of our study is related to the findings of other researchers that EI is related to the level of human health [43,44], PA [7], and rapid decision-making [45]. Based on the cognitive reflection assessment [36], we found that, in contrast to EI, cognitive reflection is not associated with MVPA.

\section{Limitations and Directions for Future Research}

This study examined adult people's structure of PA, stress, LT, EI, and overall health in Lithuanian people. To estimate the observational processes mentioned above aspects, longitudinal studies are particularly urgent. Moreover, this study focused on European adult people (Lithuanian), thus the cultural differences about a similar topic are also particularly needed. In addition, future studies are highly needed to include the adolescent stage of age observations in a similar type of study.

\section{Conclusions}

This research study clearly showed that during the lifespan of 18-24 and 25-34 years (young adults) there was a sharp increase in overweight and obesity, a decrease in PA (and especially vigorous PA; and this was particularly evident in a male), while research participants felt less stress and depression, subjective assessment of health did not change, and EI increased steadily with age (18-24 to 65-74 years). The higher EI of the research participants-18-24 to 65-74 years of age-the higher their moderate-to-vigorous PA and the less stress and depression they felt. It was found that "vigorous PA did not depend on reflective thinking". Thus, EI helps one to feel better, but "masks" a huge scourge of health deterioration-overweight and obesity and physical inactivity. Therefore, it can be said that both females and males prefer PA "with a hot heart rather than a cold mind." This conclusion is based on the fact that females and males who have the highest EI also have the highest MVPA, although LT is not associated with MVPA.

Author Contributions: A.S. (Albertas Skurvydas) participated in the design of the study and contributed to data collection and reduction/analysis and interpretation of the results. A.L., M.L., R.D., N.F. and A.S. (Asta Sarkauskiene) contributed to data reduction and analysis. D.M. and D.V. participated in the design of the study and contributed to data collection. All authors have read and agreed to the published version of the manuscript.

Funding: This research received no external funding.

Institutional Review Board Statement: Ethic committee by the Klaipeda University approval to conduct this research was provided (protocol No. STIMC-BTMEK-08). The study was conducted according to the guidelines of the Declaration of Helsinki (Revised 2013) and National guidelines for biomedical and health research involving human participants (2017).

Informed Consent Statement: The purpose of the survey, introduction and the length of the survey were added within the web-based open E-survey. A successful return of the completed survey was considered as consent by the participant.

Data Availability Statement: The data presented in this study are available on request from the corresponding author.

Conflicts of Interest: The authors declare no conflict of interest.

\section{References}

1. Pedersen, B.K.; Saltin, B. Exercise as medicine-Evidence for prescribing exercise as therapy in 26 different chronic diseases. Scand. J. Med. Sci. Sports 2015, 25, 1-72. [CrossRef]

2. Luan, X.; Tian, X.; Zhang, H.; Huang, R.; Li, N.; Chen, P.; Wang, R. Exercise as a prescription for patients with various diseases. J. Sport Health Sci. 2019, 8, 422-441. [CrossRef]

3. Bull, F.C.; Al-Ansari, S.S.; Biddle, S.; Borodulin, K.; Buman, M.P.; Cardon, G.; Carty, C.; Chaput, J.P.; Chastin, S.; Chou, R.; et al. World Health Organization 2020 guidelines on physical activity and sedentary behavior. Br. J. Sports Med. 2020, 54, 1451-1462. [CrossRef] 
4. $\quad$ Erickson, K.I.; Hillman, C.; Stillman, C.M.; Ballard, R.M.; Bloodgood, B.; Conroy, D.E.; Macko, R.; Marquez, D.X.; Petruzzello, S.J.; Powell, K.E.; et al. Physical Activity, Cognition, and Brain Outcomes: A Review of the 2018 Physical Activity Guidelines. Med. Sci. Sports Exerc. 2019, 51, 1242-1251. [CrossRef]

5. Zlibinaite, L.; Skurvydas, A.; Kilikeviciene, S.; Solianik, R. Two Months of Using Global Recommendations for Physical Activity Had No Impact on Cognitive or Motor Functions in Overweight and Obese Middle-Aged Women. J. Phys. Act. Health 2020, 18, 52-60. [CrossRef]

6. Žlibinaitè, L.; Solianik, R.; Vizbaraitè, D.; Mickevičienė, D.; Skurvydas, A. The Effect of Combined Aerobic Exercise and Calorie Restriction on Mood, Cognition, and Motor Behavior in Overweight and Obese Women. J. Phys. Act. Health 2020, 17, 204-210. [CrossRef] [PubMed]

7. Laborde, S.; Dosseville, F.; Allen, M.S. Emotional intelligence in sport and exercise: A systematic review. Scand. J. Med. Sci. Sports 2016, 26, 862-874. [CrossRef] [PubMed]

8. $\quad$ Ekelund, U.; Tarp, J.; Steene-Johannessen, J.; Hansen, B.H.; Jefferis, B.; Fagerland, M.W.; Whincup, P.; Diaz, K.M.; Hooker, S.P.; Chernofsky, A.; et al. Dose-response associations between accelerometry measured physical activity and sedentary time and all-cause mortality: A systematic review and harmonized meta-analysis. BMJ 2019, 366, 14570. [CrossRef]

9. Rey Lopez, J.P.; Sabag, A.; Martinez Juan, M.; Rezende, L.F.M.; Pastor-Valero, M. Do vigorous-intensity and moderate-intensity physical activities reduce mortality to the same extent? A systematic review and meta-analysis. BMJ Open Sport Exerc. Med. 2020, 6, e000775. [CrossRef] [PubMed]

10. Skurvydas, A.; Mamkus, G.; Kamandulis, S.; Dudoniene, V.; Valanciene, D.; Westerblad, H. Mechanisms of force depression caused by different types of physical exercise studied by direct electrical stimulation of human quadriceps muscle. Eur. J. Appl. Physiol. 2016, 116, 2215-2224. [CrossRef]

11. Bennie, J.A.; De Cocker, K.; Teychenne, M.J.; Brown, W.J.; Biddle, S.J.H. The epidemiology of aerobic physical activity and muscle-strengthening activity guideline adherence among 383,928 U.S. adults. Int. J. Behav. Behav. Nutr. Nutr. Phys. Act. 2019, 16, 34. [CrossRef]

12. Lisinskiene, A.; Juskeliene, V. Links between Adolescents' Engagement in Physical Activity and Their Attachment to Mothers, Fathers, and Peers. Int. J. Environ. Res. Public Health 2019, 16, 866. [CrossRef]

13. Wong, M.C.S.; Huang, J.; Wang, J.; Chan, P.S.F.; Lok, V.; Chen, X.; Leung, C.; Wang, H.H.X.; Lao, X.Q.; Zheng, Z.J. Global, regional and time-trend prevalence of central obesity: A systematic review and meta-analysis of 13.2 million subjects. Eur. J. Epidemiol. 2020, 35, 673-683. [CrossRef] [PubMed]

14. Pedersen, B.K. The Physiology of Optimizing Health with a Focus on Exercise as Medicine. Annu. Rev. Physiol. 2019, 81, 607-627. [CrossRef]

15. Pedersen, E.S.L.; Mortensen, L.H.; Brage, S.; Bjerregaard, A.L.; Aadahl, M. Criterion validity of the Physical Activity Scale (PAS2) in Danish adults. Scand. J. Public Health 2018, 46, 726-734. [CrossRef] [PubMed]

16. Lazarevich, I.; Camacho, M.E.I.; del Consuelo Velázquez-Alva, M.; Zepeda, M.Z. Relationship among obesity, depression, and emotional eating in young adults. Appetite 2016, 107, 639-644. [CrossRef]

17. Konttinen, H.; Van Strien, T.; Männistö, S.; Jousilahti, P.; Haukkala, A. Depression, emotional eating and long-term weight changes: A population-based prospective study. Int. J. Behav. Nutr. Phys. Act. 2019, 16, 28. [CrossRef]

18. Jang, H.J.; Kim, B.S.; Won, C.W.; Kim, S.Y.; Seo, M.W. The relationship between psychological factors and weight gain. Korean J. Fam. Med. 2020, 41, 381-386. [CrossRef] [PubMed]

19. Paulino, D.S.M.; Pinho-Pompeu, M.; Raikov, F.; Freitas-Jesus, J.V.; Machado, H.C.; Surita, F.G. Papel dos comportamentos relacionados à saúde no ganho de peso gestacional em mulheres com sobrepeso e obesidade: Um estudo transversal. Rev. Bras. Ginecol. E Obs. 2020, 42, 316-324. [CrossRef]

20. Creber, R.M.M.; Fleck, E.; Liu, J.; Rothenberg, G.; Ryan, B.; Bakken, S. Identifying the complexity of multiple risk factors for obesity among urban Latinas. J. Immigr. Minor. Health 2017, 19, 275-284. [CrossRef]

21. Guthold, R.; Stevens, G.A.; Riley, L.M.; Bull, F.C. Worldwide trends in insufficient physical activity from 2001 to 2016 : A pooled analysis of 358 population-based surveys with 1.9 million participants. Lancet Glob. Health 2018, 6, e1077-e1086. [CrossRef]

22. Matikainen-Ankney, B.A.; Kravitz, A.V. Persistent effects of obesity: A neuroplasticity hypothesis. Ann. N. Y. Acad. Sci. 2018, 1428, 221-239. [CrossRef]

23. Saruco, E.; Pleger, B. A Systematic Review of Obesity and Binge Eating Associated Impairment of the Cognitive Inhibition System. Front. Nutr. 2021, 8, 609012. [CrossRef]

24. Luppino, F.S.; de Wit, L.M.; Bouvy, P.F.; Stijnen, T.; Cuijpers, P.; Penninx, B.W.; Zitman, F.G. Overweight, obesity, and depression: A systematic review and meta-analysis of longitudinal studies. Arch. Gen. Psychiatry 2010, 67, 220-229. [CrossRef]

25. Aparicio, E.; Canals, J.; Arija, V.; De Henauw, S.; Michels, N. The role of emotion regulation in childhood obesity: Implications for prevention and treatment. Nutr. Res. Rev. 2016, 29, 17-29. [CrossRef] [PubMed]

26. Evans, J.S. Dual-processing accounts of reasoning, judgment, and social cognition. Annu. Rev. Psychol. 2008, 59, 255-278. [CrossRef] [PubMed]

27. Maxwell, A.L.; Gardiner, E.; Loxton, N.J. Investigating the relationship between reward sensitivity, impulsivity, and food addiction: A systematic review. Eur. Eat. Disord. Rev. 2020, 28, 368-384. [CrossRef]

28. World Medical Association. World Medical Association Declaration of Helsinki: Ethical principles for medical research involving human subjects. JAMA 2013, 310, 2191-2194. [CrossRef] 
29. Behera, S.K.; Das, S.; Xavier, A.S.; Selvarajan, S.; Anandabaskar, N. Indian Council of Medical Research's National Ethical Guidelines for biomedical and health research involving human participants: The way forward from 2006 to 2017 . Perspect. Clin. Res. 2019, 10, 108-114.

30. Matthiessen, J.; Biltoft-Jensen, A.; Rasmussen, L.B.; Hels, O.; Fagt, S.; Groth, M.V. Comparison of the Danish physical activity questionnaire with a validated position and motion instrument. Eur. J. Epidemiol. 2008, 23, 311-322. [CrossRef]

31. Aadahl, M.; Jørgensen, T. Validation of a new self-report instrument for measuring physical activity. Med. Sci. Sports Exerc. 2003, 3, 1196-1202. [CrossRef] [PubMed]

32. Cohen, S.; Kamarck, T.; Mermelstein, R. A global measure of perceived stress. J. Health Soc. Behav. 1983, 24, 385-396. [CrossRef] [PubMed]

33. Schutte, N.S.; Malouff, J.M.; Hall, L.E.; Haggerty, D.J.; Cooper, J.T.; Golden, C.J.; Dornheim, L. Development and validation of a measure of emotional intelligence. Pers. Individ. Differ. 1998, 25, 167-177. [CrossRef]

34. Patton, J.H.; Stanford, M.S.; Barratt, E.S. Factor structure of of the Barratt impulsiveness scale. J. Clin. Psychol. 1995, 51, 768-774. [CrossRef]

35. Frederick, S. Cognitive reflection and decision making. J. Econ. Perspect. 2005, 19, 25-42. [CrossRef]

36. Stone, A.A.; Schneider, S.; Broderick, J.E. Psychological stress declines rapidly from age 50 in the United States: Yet another well-being paradox. J. Psychosom. Res. 2017, 103, 22-28. [CrossRef]

37. Heckhausen, J.; Wrosch, C.; Schulz, R. A motivational theory of life-span development. Psychol. Rev. 2010, 117, 32-60. [CrossRef]

38. Aleksovska, K.; Puggina, A.; Giraldi, L.; Buck, C.; Burns, C.; Cardon, G.; Carlin, A.; Chantal, S.; Ciarapica, D.; Colotto, M.; et al . Biological determinants of physical activity across the life course: A "Determinants of Diet and Physical Activity" (DEDIPAC) umbrella systematic literature review. Sports Med. Open 2019, 5, 2. [CrossRef]

39. Koeneman, M.A.; Verheijden, M.W.; Chinapaw, M.J.; Hopman-Rock, M. Determinants of physical activity and exercise in healthy older adults: A systematic review. Int. J. Behav. Nutr. Phys. Act. 2011, 8, 142. [CrossRef] [PubMed]

40. Chooi, Y.C.; Ding, C.; Magkos, F. The epidemiology of obesity. Metabolism 2019, 92, 6-10. [CrossRef]

41. Peters, A.; McEwen, B.S. Stress habituation, body shape and cardiovascular mortality. Neurosci. Biobehav. Rev. 2015, 56, 139-150. [CrossRef]

42. Goldstein, J.M.; Hale, T.; Foster, S.L.; Tobet, S.A.; Handa, R.J. Sex differences in major depression and comorbidity of cardiometabolic disorders: Impact of prenatal stress and immune exposures. Neuropsychopharmacology 2019, 44, 59-70. [CrossRef] [PubMed]

43. Schutte, N.S.; Malouff, J.M.; Thorsteinsson, E.B.; Bhullar, N.; Rooke, S.E. A meta-analytic investigation of the relationship between emotional intelligence and health. Pers. Indiv. Differ. 2007, 42, 921-933. [CrossRef]

44. Sarrionandia, A.; Mikolajczak, M. A meta-analysis of the possible behavioural and biological variables linking trait emotional intelligence to health. Health Psychol. Rev. 2020, 14, 220-244. [CrossRef] [PubMed]

45. Mayer, J.D.; Roberts, R.D.; Barsade, S.G. Human abilities: Emotional intelligence. Annu. Rev. Psychol. 2008, 59, 507-536. [CrossRef] 